\title{
Development of inferences over elementary-school grades: IV. Affective bias as a determinant of inferences
}

\author{
MELVIN H. MARX \\ Western Carolina University, Cullowhee, North Carolina, and Florida Institute of Technology \\ Melbourne, Florida \\ and \\ BRUCE B. HENDERSON \\ Western Carolina University, Cullowhee, North Carolina
}

\begin{abstract}
The effect of affective bias on the inferences made by 239 children in Grades 1-8 was examined. Children heard brief stories that presented the main character in a positive or negative light. "Yes" responses to test items indicated an inference of a negative outcome for the main character from ambiguous information. An unintended outcome was that preexisting biases about the characters had a major impact on children's inferential responses. A manipulation involving a within-story bias influenced children's inferring a negative outcome in the expected direction only when the negative characterization of the story was concordant with a preexisting bias in regard to the character. Some grade differences were apparent, but were not developmentally systematic.
\end{abstract}

This experiment was designed to assess the role of affect in the development of inferential bias in memory. It is an extension of a series of studies examining the course of development of inferences over the elementary-school years (Marx, 1991, 1992a, 1992b). The role of affective quality does not appear to have been a focus of research on inferences (cf. recent literature reviews, Keenan, Potts, Golding, \& Jennings, 1990; McKoon \& Ratcliff, 1990; Singer, 1988). Affect was manipulated in this study by casting the main characters in short stories read to children in either a distinctly positive or a distinctly negative light. Information that followed the creation of the bias was incomplete so that either positive or negative outcomes could be inferred. Children were then tested by having them indicate whether or not there had been a negative outcome in the story. Inferred harmful outcomes thus were measured as a function of the negative or positive treatment of the main character.

\section{METHOD}

\section{Subjects}

The children who took part in the study were in the 1st-8th grades in a parochial school in a southeastern state. They ranged from 6 to 14 years of age. There were 31 1st-graders ( 20 males, 11 females), 27 2nd-graders ( 7 males, 20 females), 27 3rd-graders ( 14 males, $13 \mathrm{fe}-$ males), 31 4th-graders (13 males, 18 females), 34 5th-graders (14 males, 20 females), 31 6th-graders (16 males, 15 females), 32 7th-graders (15 males, 17 females), and 26 8th-graders (10 males, 16 females).

We thank Howard C. Avril, Principal, and the participating teachers and students at St. Helen School, Vero Beach, FL, for their aid in the collection of data. Correspondence should be addressed to either author at the Department of Psychology, Western Carolina University, Cullowhee, NC 28723.

\section{Procedure}

The children were read two-sentence stories in their classrooms, including 2 practice stories and 10 stories involving characters that were presented with positive or negative attributes. The first sentence in each story cast the major character in a positive or negative light. The second sentence contained ambiguous information about a possible outcome for the main character. For example, in "The Canary," the canary was described as having sung loud and long and as being friendly with strangers. Then a statement was made about the pet cat's knocking over the canary's cage. The test item asked if the canary had been caught by the cat. A "yes" response was assumed to indicate that a child had made a harmful inference about the canary.

Half the stories presented the main character in a positive light, and the other half presented the main character in a negative light. An example of the latter was the story "The Crow." The crow was described as a bird who stayed near the playground and sometimes flew into the hair of one of the children. The second sentence stated that a hunter was hired to scare off some of the bird pests in the neighborhood because it was located near an airport and the birds were hazardous when planes were departing or arriving. The test question asked if the crow was one of the birds that was scared off by the hunter.

The two practice stories, one with a positively presented character and one with a negatively presented character, had clearly stated outcomes. For example, the story "The movie star was very well liked by everyone and was never too busy to give her autograph to fans. One day there was a bad fire in the studio, but she was not there" was followed by the test item, "Was the movie star hurt in the fire?" The characteristics of the stories are summarized in Table 1.

Two forms of the 10 target stories were constructed with the attributes of the main characters counterbalanced for positive and negative characterization. Prior to answering the test questions, the children rated how much they liked each character on a scale of "very much," "some," "not much," or "not at all."

\section{RESULTS}

\section{Preliminary Considerations}

An unexpected outcome was that the nature of the main characters had an enormous influence on whether the first- 
Table 1

Summary of Story Characteristics

\begin{tabular}{|c|c|c|c|}
\hline \multirow{2}{*}{$\begin{array}{c}\text { Main } \\
\text { Character }\end{array}$} & \multicolumn{2}{|c|}{ Affective Treatment } & \multirow[b]{2}{*}{ Inference at Test } \\
\hline & Form A & Form B & \\
\hline Kitten & + & - & got lost \\
\hline Cow & + & - & attacked by bull \\
\hline Janitor & - & + & hurt in fall \\
\hline Lioness* & + & - & caught deer \\
\hline Crow & - & + & scared off \\
\hline Elephant & + & - & killed by villagers \\
\hline Ice-cream man & - & + & truck damaged in wreck \\
\hline Canary & + & - & caught by cat \\
\hline Billy goat & - & + & sold by farmer \\
\hline Puppy & + & - & hit by car \\
\hline
\end{tabular}

*Not scored because of error in affective loading of outcome and counterbalancing error.

sentence characterization of the story was effective or not. Preliminary analyses indicated that when the main character was a kitten, cow, elephant, canary, or puppy and was presented in a negative light, the children were resistant to making inferences that indicated negative outcomes for the character. When the main character was a janitor, crow, ice-cream man, or billy goat presented in a negative light, no such resistance occurred. Although interesting in its own right, this result was not pertinent to the objectives of the study; therefore, the results were analyzed separately for the two forms. One additional problem was that one of the stories was written incorrectly, causing an imbalance in the number of positive and negative characterizations on the forms, so responses were adjusted for use in the data analysis by calculating means.

The children's responses to the two practice items provide evidence about memory without inferences. One item on each form presented the main character in a positive light, and one presented the main character in a negative light. A "yes" or "no" response to the test item indicated correct memory for an explicit statement in the practice story. Relatively few errors were made. For Form A, the overall accuracy rate for the two practice items was $86 \%$; over half of these errors were made by 1 st-graders. For Form B, the overall accuracy rate was $95 \%$.

\section{Form A: A Priori Positive Characters in a Positive Light}

Form A consisted of the items that presented the unanticipated positive characters (kitten, canary, etc.) in a positive light and the unanticipated less positive characters (janitor, crow, etc.) in a negative light. The children in Grades $1,4,5$, and 8 received this form. The children's ratings of the characters and their inferential responses ("yes" responses to the test questions, indicating an undesirable consequence for the character) were analyzed in a 4 (grade) $\times 2$ (sex) $\times 2$ (positive vs. negative characterization) analysis of variance with repeated measures on the last factor. The mean likability ratings and inferential responses are presented in Table 2 .

Ratings. Main effects of grade $[F(3,112)=5.05, p<$ .01] and positive versus negative characterization $[F(1,112)=71.12, p<.01]$ were conditioned by a grade $\times$ positive-negative interaction $[F(3,112)=6.85$, $p<.01]$ and a sex $\times$ positive-negative interaction $[F(1,112)=4.42, p<.05]$, respectively.

Simple effects analyses indicated higher ratings for positive main characters at Grades 4, 5, and $8(p<.05$ ], but not at Grade 1. Both males and females rated positive characters more positively, but the difference was greater for females ( 2.0 for positive characters vs. 1.5 for negative characters among males, and 2.2 vs. 1.4 among females).

Inferences. A reliable main effect of positive versus negative characterization on the likelihood of a "yes" response to the test questions $[F(1,112)=134.23, p<.01]$ was conditioned by a grade $\times$ positive-negative interaction $[F(3,112)=3.21, p<.05]$. Inferences of negative outcomes were more likely for negative characterizations at each grade level, but the difference was larger for some grades than for others (see Table 2). Overall, the children were more likely to make harmful inferences about the negatively presented characters than about those who had been presented in a positive way.

\section{Form B: A Priori Negative Characters in a Positive Light}

The mean responses for the likability ratings and "yes" responses to the test items for Form B are presented in Table 3.

Ratings. A positive versus negative characterization main effect $[F(1,108)=38.01, p<.01]$ was conditioned by a grade $\times$ positive-negative interaction $[F(3,108)=$ $17.82, p<.01]$. Simple effects analyses indicated positivenegative differences only at Grades 6 and $7(p<.05)$.

Inferences. The main effect of positive versus negative characterization $[F(1,110)=44.04, p<.01]$ was again conditioned by a grade $\times$ positive-negative inter-

Table 2

Form A: Mean Proportion of Harmful Inference Responses and Mean Likability Ratings for Positive and Negative Affective Treatment Characterizations by Grade, Across Sex

\begin{tabular}{cccccc}
\hline & \multicolumn{2}{c}{ Harmful Inference } & & \multicolumn{2}{c}{ Rating } \\
\cline { 2 - 3 } \cline { 5 - 6 } Grade & $\begin{array}{c}\text { Positive } \\
\text { Treatment }\end{array}$ & $\begin{array}{c}\text { Negative } \\
\text { Treatment }\end{array}$ & & $\begin{array}{c}\text { Positive } \\
\text { Treatment }\end{array}$ & $\begin{array}{c}\text { Negative } \\
\text { Treatment }\end{array}$ \\
\hline 1 & .46 & .69 & & 2.1 & 1.9 \\
4 & .33 & .79 & & 2.0 & 1.5 \\
5 & .35 & .66 & & 2.2 & 1.1 \\
8 & .37 & .69 & & 2.0 & 1.3 \\
\hline
\end{tabular}

Table 3

Form B: Mean Proportion of Harmful Inference Responses and Mean Likability Ratings for Positive and Negative Affective Treatment Characterizations by Grade, Across Sex

\begin{tabular}{cccccc}
\hline & \multicolumn{2}{c}{ Harmful Inference } & & \multicolumn{2}{c}{ Rating } \\
\cline { 2 - 3 } \cline { 5 - 6 } Grade & $\begin{array}{c}\text { Positive } \\
\text { Treatment }\end{array}$ & $\begin{array}{c}\text { Negative } \\
\text { Treatment }\end{array}$ & & $\begin{array}{c}\text { Positive } \\
\text { Treatment }\end{array}$ & $\begin{array}{c}\text { Negative } \\
\text { Treatment }\end{array}$ \\
\hline 2 & .52 & .39 & & 1.8 & 1.9 \\
3 & .56 & .31 & & 2.0 & 1.7 \\
6 & .57 & .46 & & 1.7 & 1.4 \\
7 & .58 & .26 & & 2.2 & 1.1 \\
\hline
\end{tabular}


action $[F(3,110)=2.93, p<.05]$. Simple effects analyses indicated positive-negative differences $(p<.05)$ for Grades 2, 3, and 7, but not for Grade 6. Contrary to the findings with Form A, on Form B the children were more likely to make harmful inferences about the positively presented main characters than about the negatively presented characters.

\section{DISCUSSION}

A major conclusion to be drawn from these data is that the making of inferences, and their biasing effect on memory, can be influenced by the positive or negative affective flavor imparted to characters by the treatment they are accorded in narratives.

An even stronger, clearly commonsense conclusion is that the preexperimental affective status of narrative characters is a major determinant of the degree to which inferences are generated and of the type of inferences (e.g., positive or negative) likely to be drawn. This is most clearly suggested by the adventitious finding that certain of the characters in the stories were protected from the making of harmful inferences, and so can be presumed to have been positively regarded, whereas other characters were not so protected. Moreover, form differences suggested that, to a degree, characters without a preexisting positive bias benefited less from a contemporaneous positive casting in the story than did their positively regarded counterparts.

In future research on this problem, therefore, it will be necessary to take into account the preexperimental affective status of characters, as well as the affective treatment, as potentially important and independently manipulable variables.

\section{REFERENCES}

Keenan, J. M., Potts, G. R., Golding, J. M., \&ennings, T. M (1990). Which elaborative inferences are drawn during reading? A question of methodology. In D. A. Balota, G. B. Flores d'Arcais, \& K. Rayner (Eds.), Comprehension processes in reading (pp. 377402). Hillsdale, NJ: Erlbaum.

MARX, M. H. (1991). Development of inferences over elementary-school grades: I. Recall and association of implicit words. Bulletin of the Psychonomic Society, 29, 460-462.

MARX, M. H. (1992a). Development of inferences over elementaryschool grades: II. Retention of explicit and implicit words. Bulletin of the Psychonomic Society, 30, 167-169.

MARX, M. H. (1992b). Development of inferences over elementaryschool grades: III. Verbatim and forward-consequence inferential errors made by regular and gifted students. Bulletin of the Psychonomic Society, 30, 353-355.

McKoon, G., Ratcliff, R. (1990). Dimensions of inference. In A. C. Graesser \& G. H. Bower (Eds.), The psychology of learning and motivation (Vol. 25, pp. 403-421). New York: Academic Press.

SINGER, M. (1988). Inferences in reading comprehension. In M. Daneman, G. MacKinnon, \& T. Weller (Eds.), Reading research: Advances in theory and practice (Vol. 6, pp. 177-219). New York: Academic Press.

(Manuscript received November 3, 1992.) 